\title{
The effect of long-term volleyball training on the level of somatic parameters of female volleyball players in various age categories
}

\author{
Petr Kutáč Corresp., ${ }^{1}$, David Zahradník ${ }^{1}$, Miroslav Krajcigr ${ }^{1}$, Václav Bunc ${ }^{2}$ \\ ${ }^{1}$ Human Motion Diagnostics Center, University of Ostrava, Ostrava, Czech Republic \\ 2 Charles University Prague, Prague, Czech Republic \\ Corresponding Author: Petr Kutáč \\ Email address: petr.kutac@osu.cz
}

Volleyball is an exceedingly popular physical activity in the adolescent population, especially with females. The study objective was to assess the effect of volleyball training and natural ontogenetic development on the somatic parameters of adolescent girls. The study was implemented in a group of 130 female volleyball players (aged 12.3 $\pm 0.5-$ $18.1 \pm 0.6$ years) along with 283 females from the general population (aged $12.3 \pm 0.5-$ 18.2 \pm 0.5 years). The measured parameters included: body height $(\mathrm{cm})$, body mass $(\mathrm{kg})$, body fat $(\mathrm{kg}, \%)$, visceral fat $\left(\mathrm{cm}^{2}\right)$, body water $(\mathrm{I})$, fat free mass $(\mathrm{kg})$ and skeletal muscle mass $(\mathrm{kg}, \%)$. Starting at the age of 13 , the volleyball players had significantly lower body fat ratio and visceral fat values than those in the general population $(p<0.001$ in body fat $\%$ and $p<0.01$ in visceral fat). In volleyball players, the mean body fat (\%) values were $17.7 \pm 6.6$ in 12 -year-old players, $16.7 \pm 4.9$ in 13-year-old players, $18.5 \pm 3.9$ in 16-year-old players, and 19.3 \pm 3.1 in 18-year-old players. In the general population, the mean body fat

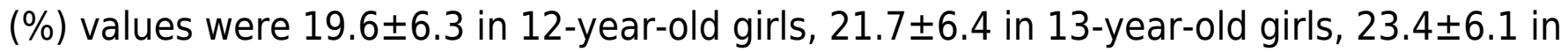

16-year-old girls, and $25.8 \pm 7.0$ in 18-year-old girls. The visceral fat $\left(\mathrm{cm}^{2}\right)$ mean values were $36.4 \pm 19.3$ in 12-year-old players, $39.2 \pm 16.3$ in 13-year-old players, $45.7 \pm 14.7$ in 16 year-old players, and $47.2 \pm 12.4$ in 18-year-old players. In the general population, the mean visceral fat $\left(\mathrm{cm}^{2}\right)$ values were $41.4 \pm 21.1$ in 12-year-old girls, $48.4 \pm 21.5$ in 13-year-

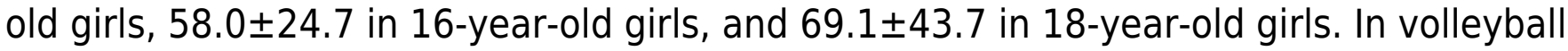
players, lower body fat ratio corresponded with a higher skeletal muscle mass ratio. The differences found in skeletal muscle mass ratio were also significant starting at the age of 13 ( $p<0.001)$. The mean skeletal muscle mass (\%) values were $44.1 \pm 3.4$ in 12-year-old volleyball players, 45.4 22.5 in 13-year-old players, 45.0 \pm 2.2 in 16-year-old players, and $44.7 \pm 1.8$ in 18-year-old players. In the general population, the mean skeletal muscle mass (\%) values were $42.8 \pm 3.2$ in 12-year-old girls, $42 . \pm 4.1$ in 13-year-old girls, $41.9 \pm 3.3$ in 16Peer) reviewing PDF | (2020:06:49601:1:0:NEW 10 Aug 2020) 
year-old girls, and 40.6 43.7 in 18-year-old girls. Differences in body composition between the individual age groups were similar between the volleyball players and girls in the general population. The results indicate that regular volleyball training influences the body composition of young females however the development of body composition parameters is subject to their ontogenetic development. 
1 The effect of long-term volleyball training on the level of somatic parameters of female

2 volleyball players in various age categories

3

4 Petr Kutáčํㅗ David Zahradník ${ }^{1}$, Miroslav Krajcigr ${ }^{1}$, Václav Bunc ${ }^{2}$

5

$6{ }^{1}$ Human Motion Diagnostics Center, University of Ostrava, Faculty of Education, Ostrava,

7 Czech Republic

$8 \quad{ }^{2}$ Faculty of Physical Education and Sport, Charles University, Praha, Czech Republic

9

10 Corresponding author:

11 Petr Kutáč

12 Varenská 40a, Ostrava 701 03, Czech Republic

13 Email address: petr.kutac@osu.cz

14

15 


\section{Abstract}

Volleyball is an exceedingly popular physical activity in the adolescent population, especially with females. The study objective was to assess the effect of volleyball training and natural ontogenetic development on the somatic parameters of adolescent girls. The study was implemented in a group of 130 female volleyball players (aged 12.3 $\pm 0.5-18.1 \pm 0.6$ years) along with 283 females from the general population (aged 12.3 $\pm 0.5-18.2 \pm 0.5$ years). The measured parameters included: body height $(\mathrm{cm})$, body mass $(\mathrm{kg})$, body fat $(\mathrm{kg}, \%)$, visceral fat $\left(\mathrm{cm}^{2}\right)$, body water (1), fat free mass $(\mathrm{kg})$ and skeletal muscle mass $(\mathrm{kg}, \%)$. Starting at the age of 13 , the volleyball players had significantly lower body fat ratio and visceral fat values than those in the general population $(\mathrm{p}<0.001$ in body fat $\%$ and $p<0.01$ in visceral fat). In volleyball players, the mean body fat $(\%)$ values were $17.7 \pm 6.6$ in 12 -year-old players, $16.7 \pm 4.9$ in 13 -year-old players, $18.5 \pm 3.9$ in 16-year-old players, and $19.3 \pm 3.1$ in 18 -year-old players. In the general population, the mean body fat (\%) values were $19.6 \pm 6.3$ in 12-year-old girls, $21.7 \pm 6.4$ in 13 -year-old girls, $23.4 \pm 6.1$ in 16-year-old girls, and $25.8 \pm 7.0$ in 18 -year-old girls. The visceral fat $\left(\mathrm{cm}^{2}\right)$ mean values were $36.4 \pm 19.3$ in 12 -year-old players, $39.2 \pm 16.3$ in 13 -year-old players, $45.7 \pm 14.7$ in 16 year-old players, and 47.2 \pm 12.4 in 18 -year-old players. In the general population, the mean visceral fat $\left(\mathrm{cm}^{2}\right)$ values were $41.4 \pm 21.1$ in 12-year-old girls, $48.4 \pm 21.5$ in 13 -year-old girls, $58.0 \pm 24.7$ in 16-year-old girls, and $69.1 \pm 43.7$ in 18 -year-old girls. In volleyball players, lower body fat ratio corresponded with a higher skeletal muscle mass ratio. The differences found in skeletal muscle mass ratio were also significant starting at the age of $13(p<0.001)$. The mean skeletal muscle mass (\%) values were $44.1 \pm 3.4$ in 12 -year-old volleyball players, $45.4 \pm 2.5$ in 13 year-old players, $45.0 \pm 2.2$ in 16-year-old players, and $44.7 \pm 1.8$ in 18 -year-old players. In the general population, the mean skeletal muscle mass (\%) values were $42.8 \pm 3.2$ in 12-year-old 
girls, 42. \pm 4.1 in 13-year-old girls, $41.9 \pm 3.3$ in 16-year-old girls, and 40.6 \pm 3.7 in 18-year-old girls. Differences in body composition between the individual age groups were similar between the volleyball players and girls in the general population. The results indicate that regular volleyball training influences the body composition of young females however the development of body composition parameters is subject to their ontogenetic development.

Keywords: body composition, parameter differences, volleyball players, general population

\section{INTRODUCTION}

Volleyball is currently considered to be a dynamic game, during which low intensity and high intensity movements alternate. The high intensity movements include jumps, shuffles and rapid changes in direction (Calleja-Gonzalez et al., 2019). The offensive and defensive skills in volleyball are characterized as double-leg take-off and double-leg or single-leg landings (Tillman et al., 2004a; Lobbietti et al., 2010; Zahradnik et al., 2017). A study by Tillman et al. (2004b) showed 1,087 jump-landings in two matches among four NCAA Division IA female volleyball teams. A study by Lobietti et al. (2010) reported 2,022/2,273 jump-landings for male/female players in six matches in each category of the Italian league. Similarly, Zahradnik et al. (2017) showed 992/1,375 jump-landings during three matches in elite volleyball teams in the Czech Republic. The total intensity of the movements in volleyball can be measured at 6 METs (Scribbans et al., 2015), which is considered to be vigorous (Ainsworth et al., 2011). Therefore, a corresponding level of physical conditioning is required to effectively cope with the load in the long term. This physical conditioning is achieved with regular physical activity, which is performed during the training process. The training process in volleyball starts in the period of 
62 the second childhood (Infans II), which is related to the age categories in the system of

63

64

65

66

67

68

69

70

71

72

73

74

75

competitions in the Czech Republic organised by the Czech Volleyball Federation. The

competitions organised within the Mini-volleyball in Colours project are for children from the age of nine. The long-term preparation should influence the development of specific physical skills as well as the somatic parameters of the volleyball players. In particular, on their body composition as it is a result of the level of adaptation of the organism to the load within the conditional preparation (Tota et al., 2019). This adaptation is manifested not only in the motor performance of the athlete, but also on their physical fitness and health (Malá et al., 2015).

Regular and adequate training since childhood should not only lead to the development of fitness and motor performance, but also to the development of a series of personal traits of the individual (Kahlin et al., 2016; Joyner \& Loprinzi, 2018). Many of those personal traits are considered to be the predictor for adherence to physical activity (Annesi, 2004). These traits include: the ability to exert effort, determination, diligence, inclination to continue in the activity and to fulfil the task (Annesi, 2004). A regular physical activity might thus become a part of the lifestyle of these individuals. The inclusion of an adequate physical activity in one's daily routine is very important with respect to the individual's health, which may also be assessed through body composition assessment. The contribution of the physical activity to health and optimisation of body composition parameters has been documented in many studies (Haskell et al., 2007; Lazaar et al., 2007; Nelson et al., 2007; Roriz DE Oliveira et al., 2016; Bunc, 2018). The importance of adherence to physical activity since childhood is currently very important as many studies show that the amount of children's physical activity that meets the minimum level of physical activity for health benefits is decreasing (Liu et al., 2013; Sigmund et al.,2015).

Between 2011 and 2016, a stable insufficient level of physical activity is stated, with the highest 
85 occurrence being reported in the wealthiest countries (Guthold et al., 2018). In the Czech

86 Republic, the documented physical routine in children dropped by about 30\% in the last 2

87 decades. The decrease in physical activity of children is also inversely related to their age (as

88 their age increases, their spontaneous physical activity decreases) (Bunc, 2018). A question

arises as to whether or not using volleyball as the only physical activity can lead to an adjustment

90 of somatic parameters (such as body mass), increase in fitness and thus provide considerable

91 health benefits. The form and popularity of a physical activity are fundamental to its

92 habitualization in both child and adolescent populations (Ennis, 2017; Laroche, Girard, \&

93 Lemoyne, 2019). Volleyball is one of the frequently used physical activities in those age

94 categories (Liu et al., 2013; Glinkowska \& Glinkowski, 2018). Data from the Czech Volleyball

95 Association indicates it is a popular sport in the Czech Republic where the number of registered

96 children increased by $43.7 \%$ between 2008 and 2018.

97 There are several studies that have researched the body composition of female volleyball

98 players (Nikolaidis, 2013; Visnes \& Bahr, 2013; Ćopić et al., 2014; Paz et al., 2017; Valente-

99 Dos-Santos et al., 2018). These studies have analysed differences between volleyball and other

100 sports, between female volleyball players and untrained individuals, body composition in

101 relation to the game position of the players, the effect of training on body composition and the

102 occurrence of injuries, or the effect of body composition on the physical ability of players.

103 However, there is a lack of data on the development of body composition parameters in female

104 volleyball players through their ontogenetic development, which would also answer the question

105 about whether or not regular volleyball training may influence the natural ontogenetic

106 development of the parameters. The answers to these questions should guide volleyball trainers 
107 to better interpret the values of somatic body composition parameters and avoid poor conclusions

108 that might be reflected in inappropriate training plans.

109 The study objective was to assess the effect of volleyball training and natural ontogenetic

110 development on the somatic parameters of adolescent girls.

112 Two hypotheses were formulated for verification in the study.

113 H1: Volleyball training of adolescent girls significantly influences their body composition.

114 H2: The trend of long-term changes in the selected body composition parameters is influenced

115 by the natural ontogenetic development of young females.

\section{METHODS}

\section{Participants}

119 The study included a total of 413 participants (130 female volleyball players and 283 girls 120 from the control group - general population). The detailed characteristics of the number and age 121 of the participants is presented in Table 1. Participants had no medical difficulties and were not 122 currently taking any medication or food supplements. Only those who were not menstruating 123 were measured. Participants provided the information prior to the measurement. They 124 participated voluntarily and they were informed of the course of the study in advance. All 125 participants signed an informed consent prior to participation in the study (the consent was 126 signed by legal guardians for participants who were below the age of 18). The study was 127 approved by the Ethical Committee of the Faculty of Education at the University of Ostrava (PdF 128 OU č. 18/2018) and it is in compliance with the Helsinki Declaration. 
129 The age division of volleyball players is based on the competition rules of the Czech Volleyball 130 Association. Group VG1 is the category of Younger Pupils (12 years old and younger), VG2 is 131 the category of Older Pupils (13-14 years old), VG3 is the category of Cadets (15-16 years old) 132 and VG4 is the category of Juniors (17-19 years old). To be included in the study, the player had 133 to be registered in the list of a given age category in a volleyball club. All the players played the 134 highest level of competitions in the given age category in the Czech Republic. They were all 135 players from teams in the Moravian-Silesian Region. The total number of female volleyball 136 players was 810 based on an analysis of registered volleyball teams competing at the highest 137 level in the given age category in the Czech Republic. The number of the monitored players

138

139 140 represented $16 \%$ of all players in the Czech Republic. The control group included girls based on an intentional selection to avoid significant differences in the age between VG and CG.

\section{Physical activity of the participants:}

The girls in the general population had compulsory physical education twice a week. In their free time, they did not pursue any other regularly organised physical activity.

The volleyball players also had compulsory physical education twice a week. In their free time, they only pursued volleyball activities. The detailed schedule of volleyball activities during the season of competitions is presented in Table 2. The frequency and duration of matches is based on the system of the volleyball competition organisation. The data on the volume and frequency of training were obtained from responsible trainers.

Table 1 - insert here

Table 2 - insert here

\section{Procedures}


154 - October) in 2018. The volleyball players were measured in the Human Motion Diagnostic

155 Centre laboratory and CG girls were measured at schools. The measurements and data evaluation

156 were performed by the authors. All the measurements were executed with adherence to the

157 principles of measurement using the bioelectric impedance method (BIA) (Kyle et al., 2004).

158 Body height $(\mathrm{BH})$ was measured using Stadiometer InBody BSM 370 (Biospace, South Korea),

159 body mass (BM) and body composition were measured by the InBody 770 analyser (Biospace,

160 South Korea). It is a tetrapolar multi-frequency bioimpedance analyser that uses the frequency of

$1611000 \mathrm{kHz}$ for measurements and that is also a scale. The body composition parameters measured

162 were body fat (BF) and visceral fat (VFA) expressed as area $\left(\mathrm{cm}^{2}\right)$, total body water (TBW), fat

163 free mass (FFM) and skeletal muscle mass (SMM).

\section{Statistical analysis}

The normality of data division was checked by the Shapiro-Wilk test. To assess the

statistical significance of the differences in the means between the somatic parameters of the volleyball players and the girls in general population, a parametric independent t-test was used.

The level of statistical significance for all the used tests was set at $\alpha=0.05$. Practical significance was assessed using the effect of size (ES) by Cohen (Cohen's $d$ ). The $d$ value at the level of 0.2

171 indicates a minor difference, 0.5 an intermediate difference and 0.8 a major difference (Cohen, 172 1988). We considered the value of Cohen's $d \geq 0.5$ to be practically significant. We used Cohen's 173 effect of size because it enables the assessment of the size of the difference between groups 174 independent of the sample size. To verify whether or not we could consider our control group of 175 girls to be general population, we compared the values of their basic anthropometric parameters 
176 of BH, BM and the calculated BMI with the values of the $6^{\text {th }}$ Nation-wide Anthropological

177 Survey of Children and Adolescents (Kobzová et al., 2004). For comparison, we used the

178 normalization index $\left(\mathrm{N}_{\mathrm{i}}\right)$.

179 Ni calculation: $\mathrm{Ni}=\frac{M C G-M}{S D}\left(\mathrm{MCG}-\mathrm{Mean}\right.$ control group, $\mathrm{M}-$ Mean $6^{\text {th }} \mathrm{NAS}, \mathrm{SD}-$ standard

180 deviation $6^{\text {th }}$ NAS)

181

182 The Ni value in the range of $\pm 0.75 \mathrm{SD}$ shows an average development of the indicator, in the

183 range from \pm 0.76 to $1.5 \mathrm{SD}$ a below average (above average) development of the indicator, and

184 the value above \pm 1.5 SD means a highly below average (above average) development.

185

186 To verify the accuracy of the measured body composition parameters, we used the measurement

187 standardisation for the InBody 770 analyser in our laboratory. For that purpose, our laboratory

188 uses the calculation of the typical error of measurement (TEM) and intraclass correlation (ICC)

189 from three repeated consecutive measurements according to Hopkins (2000). The measurements

190 were done on 63 participants ( 24 female, 39 male) in the mean age of $21.96 \pm 2.57$ years. The

191 TEM and ICC values are presented in Table 3.

192

193 Table 3 - insert here

194

195 The statistical processing of the results was performed using IBM SPSS Statistics (Version 21;

196 IBM, Armonk, NY, USA).

197

198

RESULTS 
in Table 4. The mean values of the monitored somatic parameters and their ontogenetic

201

202

203

204

205

206

207

208

209

210

211

212

213 Table 4 - insert here

214

215

216

217

218

219

220

221 Figure 1 Means and standard deviations of somatic parameters - insert here

222 Table 5 - insert here Table 1 clearly imply that there are no differences in the individual age categories of the significant differences were found. Therefore, the differences found in the monitored somatic parameters are not the result of a different age of the girls. Considering the fact that all the between the individual age group's ontogenetic development of the monitored variables are presented in Table 5 .

The results indicate that the basic anthropometric attributes of our control group show normal development with respect to the mean values of the Czech general population. The Ni values found ranged from -0.04 to $+0.25 \mathrm{SD}$. The range of $\pm 0.75 \mathrm{SD}$ is considered to be the mean development of an attribute. Therefore, we can consider our control group to be general population.

development for both the volleyball players and the control group are presented in Figure 1 . The analysis of the differences between the means of the monitored parameters amid the individual age groups of the volleyball players and the control group is presented in Table 5. The results in volleyball players and the control group girls with respect to age. No statistically or practically monitored parameters had normal distribution, it was possible to use the parametric t-test for the comparison. The values of Cohen's d, characterising the practical significance of the differences 
No statistically or practically significant differences between VG1 and CG1 were found in

225

226

227

228

229

230

231

232

233

234

235

236

237

238

239

240

241

242

243

244

245

246 Table 6 - insert here difference $(d \geq 0.5)$.

the age category of G1 (12 years old). The value of Cohen's $d$ was lower than 0.5 in all cases. In other age categories (G2-G4), no statistically or practically significant differences between BM $(d<0.5)$ were found between the groups of volleyball players and the control groups in the corresponding age categories. Statistically significant differences were found in all other parameters and their practical significance was also confirmed. The volleyball players had significantly higher FFM values than the control group girls of the same age, even though no significant differences in BM were found. Between VG2 and CG2, we determined an intermediate difference $(d \geq 0.5)$, and we determined a major difference $(d \geq 0.8)$ in the older age categories. The higher representation of FFM also corresponds with the higher values of SMM, even when expressed as percentage of their ratio in total BM. The differences found were at the level of a major difference $(d \geq 0.8)$, an intermediate difference $(d \geq 0.5)$ was determined only when comparing SMM (kg) between VG2 and CG2. The higher FFM values in the volleyball players corresponded with significantly higher values of their TBW (statistically and practically). When comparing VG2 with CG2, we determined an intermediate difference $(d \geq 0.5)$, and we determined a major difference $(d \geq 0.8)$ in the other age categories. The BF ratio in the volleyball players was significantly lower than in the control group. In the values expressed in kilograms (BF kg), we determined an intermediate difference $(d \geq 0.5)$, and in the percentage of the BF to $\mathrm{BM}$ ratio, we determined a major difference $(d \geq 0.8)$. Also, the VFA values were significantly lower in the volleyball players. The difference found was at the level of an intermediate 
248 To assess the development and differences in the monitored somatic parameters in relation to the

249 increasing chronological age in the volleyball players and in the control group, we used the mean

250 values of the individual groups (Figure 1). We analysed the differences related to the increasing

251 age in the volleyball players separately from the control group girls. The practical significance

252 was assessed using Cohen's $d$. Between the age of 12 and 13, there was a more considerable

253 increase in BH and BM in the volleyball players $(d>0.8)$ than in the control group $(d=0.5)$. The

254 increase in BM was manifested by a more considerable increase in FFM, SMM (kg) and TBW

255 (1) ( $d>0.8)$. The development of the monitored parameters does not change in the following

256 years, both in the volleyball players and in the control group. Between the age of 13 and 16, only

257 minor differences $(d<0.5)$ were determined in BF $(\%)$, VFA and SMM $(\%)$ in both the volleyball

258 players and the control group, other parameters showed intermediate differences $(d \geq 0.5)$.

259 Between the age of 16 and 18, there were no significant differences in the volleyball players and

260 in the control group, only minor differences $(d<0.5)$ were determined. It appears that the

261 developmental tendencies do not differ, they only move towards better values in the volleyball

262 players. It is also documented by the diagram of the development of somatic parameters in

263 Figure 1.

264

265 DISCUSSION

266 To assess the physical activity represented by the participation of the volleyball players in 267 training sessions and matches (Table 2), we used the recommendations stated in expert studies..

268 A daily physical activity of vigorous or moderate intensity that lasts 60 minutes is recommended

269 for children and youth, which represents 420 minutes/week (Janssen, 2007; Troiano et al., 2008; 
270 Janssen \& Leblanc, 2010;Riebe et al., 2015 ). This volume is not met in the youngest category

271 (VG1) in the age categories we monitored, which has a physical activity of 360 minutes/week.

272 This may be one of the possible reasons there was no difference in the monitored parameters

273 between the volleyball players and the control group at the age of 12 . Another cause might be the

274 larger volume of spontaneous physical activity in the youngest girls of the general population, by

275 which the girls make up for the absence of organised physical activities. Spontaneous physical

276 activity decreases considerably as the age increases (Bunc, 2018). The decrease is then replaced

277 with volleyball training and matches in older age groups. From the age of 13 (VG2), the

278 volleyball players not only meet the recommendation of 420 minutes/week, but they also exceed

279 it. It had an effect on the statistically and practically significant differences in the monitored

280 parameters. The statistically and practically significantly higher $\mathrm{BH}$ in the volleyball players is

281 an exception as it cannot be linked to the higher volume of physical activity of the volleyball

282 players. The high increase in BH cannot be caused by different ontogenetic development. In both

283 groups (VG and CG), the girls are in the same chronological age and according to the expert

284 studies are at the end of the peak height velocity (PHV). PHV is stated in the same period for

285 girls both engaged and not engaged in sports. PHV for girls engaged in sports occurs at the age

286 of 11.8-12.3 and for those not engaged in sports it is 11.4-12.2. Later, PHV is only mentioned in

287 gymnasts (Malina \& Geithner, 2011; Malina et al., 2015). The higher BH of the volleyball

288 players is related to the rules and the essence of volleyball, whilst also being an advantage for

289 serving. Furthermore, previous research in tennis also indicates that a higher $\mathrm{BH}$ was

290 advantageous in serving and the tennis players with a higher BH served with a higher velocity

291 (Vaverka \& Cernosek, 2013). The higher BH of the volleyball players is probably caused by the

292 selection criteria of clubs focusing on girls with a higher BH. This is also confirmed by results 
293 from studies that focused on the selection of female players for the national junior volleyball

294 team. The selected players had a significantly higher BH than the players who were not selected

295 (Papadopoulou et al., 2019; Tsoukos et al., 2019). The BH results presented in scientific studies

296 correspond with the values determined in our volleyball players from VG2 (aged 13+), unless the

297 studies deal with players selected for representative purposes. The values in those studies range

298 from $167.0 \pm 8.0 \mathrm{~cm}$ to $169.0 \pm 6.0 \mathrm{~cm}$ (Nikolaidis, 2012; Papadopoulou et al., 2019; Papadopoulou

299 et al., 2020). The BH values in young female volleyball players from the representation

300 selections already exceed $170 \mathrm{~cm}$ at the age of 13 (Nikolaidis et al., 2017; Papadopoulou et al.,

301 2019). The volleyball players in our youngest age category VG1 (12 years) have lower BH

302 values than the twelve-year-old players in the study by Nikolaidis (2012) where the mean BH

303 value stated for such girls is $161.5 \pm 8.0 \mathrm{~cm}$. The difference is probably due to the fact that the

304 selection of players for A teams competing at the highest level are often moved to a higher age

305 category with regard to the lower number of players in Czech volleyball clubs.

306 Considering the fact that no statistically or practically significant differences were found in

307 the values of BM in the volleyball players and the control group, we can not only compare the

308 percentage ratio of the individual tissues in the total BM, but also their absolute values in

309 kilograms. The primarily measured parameter in the BIA method is water, therefore, it is also

310 required to analyse organism hydration as other parameters are calculated additionally on the

311 basis of the primary parameter values. The TBW values closely correspond with the volume of

312 muscle mass, presented by the SMM parameter. SMM is a body tissue that produces work and is

313 developed by regular training (Malina, 2007). This was also confirmed in the volleyball players

314 we monitored whose SMM ratio was much higher from the age category of VG3 than the CG

315 girls. The higher FFM and SMM to BM ratio in the volleyball players is also related to their 
316 considerably lower BF ratio. The differences found were higher not only than TEM used in our

317 laboratory for measurement standardisation (Table 3), but also higher than inter-daily variability,

318 which ranges from 0.7 to $1.3 \mathrm{~kg}$ and from 0.9 to $1.6 \%$ in relation to the used BIA analyser and

319 the growing interval between the individual measurements (Vicente-Rodríguez, 2012; Kutáč,

320 2015). The significantly lower BF ratio and higher SMM ratio determined in our volleyball

321 players at the age of 13 and above (VG2) when compared with $\mathrm{CG}$ is the result of their regular

322 athletic preparation and it is a condition for adequate athletic performance. Body composition,

323 especially the BF and SMM ratios, is an important factor that influences the athletic performance

324 (Nikolaidis et al., 2017; Papadopoulou et al., et al., 2019; Papadopoulou et al., 2020). The effect

325 of BF on athletic performance is described well by the correlation between the skinfold thickness

326 and performance indexes (Abakov jump, hand grip muscle strength, physical working capacity,

327 peak power, sit-and-reach test). The higher the skinfold thickness, the more negative its influence

328 (Papadopoulou et al., 2020). The same negative effect of BF was also demonstrated in a study

329 that focused on performance in the above-jump test in 13-year-old female volleyball players

330 (Nikolaidis et al., 2017). When there was absence of a difference in BF, there was also absence

331 of a difference in performance indexes (Papadopoulou et al., et al., 2019). We can only compare

332 the determined values of the soft tissue ratio (BF and SMM) with the results of a study that used

333 the same BIA analyser as we did. Therefore, we compared our results with the results of a study

334 by Ćopić et al. (2014). Even though the study authors analysed elite adult female volleyball

335 players, the differences in the BF results in our players were insignificant. The authors state the

336 mean $\mathrm{BF}$ ratio value of $17.6 \pm 2.4 \%$. The values of our players range from $16.7 \pm 4.9$ to $19.3 \pm 3.1$

$337 \%$. The largest difference was found in our oldest players (VG4), whose mean BF value was

$33819.3 \pm 3.1 \%$. Our VG2 players (13 years old) were the closest to the values of elite adult female 
339 players in the SMM ratio, the mean value of which in the aforesaid study was $46.1 \%$, which is

340 related to the fact that this age group had the lowest BF ratio. We did not find any other similar

341 data in the available scientific literature, as the values of our oldest players (VG 4), where it is

342 possible to assume that the ontogenetic development has ended and who have been trained for

343 the longest period of time, should show values that are the closest to the published values of elite

344 adult players. To assess the health condition of an individual, however, the ratio of subcutaneous

345 fat and visceral fat, need to be monitored as they are more active metabolically and its increase is

346 considered to be a risk factor not only in obesity, but also in cardiovascular diseases (Beaufrére

347 \& Morio, 2000; Van Gaal, Mertens \& De Block, 2006; Haberka et al., 2018). In this study,

348 visceral fat is expressed as an area (VFA). From the age of 13, the volleyball players had

349 significantly lower values of this fat than the control group girls. When compared with the CG

350 values, the lower BF ratio and the lower VFA values in our volleyball players are very positive

351 for their state of health, especially considering the increasing prevalence of obesity in the child

352 population ( $\mathrm{Ng}$ et al., 2014). Considering that child obesity is carried over into adulthood where

353 it may potentially increase morbidity and thus, impair the quality of life (Tsigos et al., 2008), we

354 may consider regular volleyball training to be a suitable activity for maintaining reasonable body

355 mass, including the body fat values.

356 No differences were found in the comparison of the development of the monitored

357 parameters in the volleyball players and the control group girls in relation to the increasing

358 chronological age. The values of somatic parameters gradually increase with the increasing

359 chronological age up to the age of 16 in both groups (VG, CG), after that the development slows

360 down and the differences are insignificant. The development of the monitored parameters

361 corresponds with the course of development described in expert studies (Malina \& Geithner, 
362 2011). A considerable difference in the monitored parameters in the volleyball players between

363 the age of 12 and 13 is an exception. Significant increases that can be described as major

364 differences $(d \geq 0.8)$ were found in the parameters of BH, BM, SMM (kg) and TBW. The

365 increased $\mathrm{BH}$ in the volleyball players between the age of 12 and 13 corresponds with the

366 increase in BM. The considerable increase in BM is also accompanied by a considerable increase

367 in the representation of the individual tissues (SMM, FFM, TBW), but it was not accompanied

368 by a significant increase in body fat. The gradual significant increase in BF in our volleyball

369 players probably does not occur thanks to the balanced energy intake and output. In practice, it

370 means there is no increase in body fat due to a disturbed energy balance. The amount of body fat

371 only changes within ontogenesis as a result of maturing of all the monitored girls. The energy

372 output in girls doing sports is higher than in the girls at the same age without regular sports

373 training, which increases the fitness of the girls doing sports (Nikolaidis et al., 2012).

374 The energy intake in the regular adolescent population without regular physical activity

375 ranges from $8.76 \pm 2.36 \mathrm{MJ} /$ day to $9.28 \pm 2.0 \mathrm{MJ} /$ day (Forrestal, 2011; Murakami K \&

376 Livingstone, 2016). The mean daily energy output in female volleyball players is $14.55 \pm 2.53 \mathrm{MJ}$

377 (Woodruff \& Meloche, 2012), which is a value higher by 36.2-39.8 \% when compared with the

378 values stated for individuals without regular physical activity. The daily intake of female

379 volleyball players was 14.37 $\pm 4.90 \mathrm{MJ}$ (Woodruff \& Meloche, 2012), which confirms the energy

380 balance. This energy balance is required to manage the load during training. It is thus obvious

381 that volleyball training will not lead to reduced BM, but it could prevent BF from increasing.

382 There is an increase in the energy intake in the regular population due to a lack of sufficient

383 physical activity (Vadiveloo, Zhu, \& Quatromoni, 2009), which was demonstrated as permanent 
384 in our study. It is confirmed by the significant differences in BG between VG and CG in all age

385 groups starting at VG2 and the absence of difference in BF values during ontogenesis (Table 6.).

386 Hypotheses H1 and H2 were confirmed.

387

388

389

390

391

392

393

394

395

396

397

398

399

400

401

402

403

404

405

406

\section{Limitations}

There are several limitations to this study. The first one arises from the method used for the measurement of body composition. We used the bioelectrical impedance method (BIA) which is sensitive to the hydration of the organism. All the subjects (their legal guardians) were informed of the principles that needed to be observed before the measurement, however, it is not possible to ensure and verify the actual observance of all the principles for measurement in practice. The second limitation concerns monitoring the menstrual cycle phases that may have an effect on the resulting body composition values. With regard to the fact that we were not able to monitor the phases, only the occurrence of menstrual bleeding was an exclusion criterion in the measurement. The third limitation concerns the use of the values of basic anthropometric parameters $(\mathrm{BH}, \mathrm{BM}, \mathrm{BMI})$ from $6^{\text {th }} \mathrm{NAS}$, which was implemented in 2001 . However, there have not been any updated normative values of the Czech population. The fourth limitation is the absence of checking the diet and energy balance of the monitored subjects. However, the volleyball players are not provided any common diet or a nutritionist within their training. The energy intake and output values are based on the values published in scientific studies.

\section{CONCLUSIONS}

The study results show that regular volleyball training leads to a lower body fat ratio, lower visceral fat values and a higher skeletal muscle mass ratio compared with the general population. 
407 Therefore, it is possible to recommend regular volleyball training as a physical activity for

408 maintaining adequate body mass.

409 The body fat ratio, the visceral fat and skeletal muscle mass values gradually increase with

410 the increasing age of the volleyball players. However, those changes correspond with the

411 changes in the general population. It was proven that the development of body composition

412 parameters is subject to ontogenetic development having a higher effect than the volleyball

413 training recorded.

414 Body fat is a frequently monitored parameter in training practice. Its gradual increase

415 during ontogenesis is a natural feminine effect, as the results of our study showed. This fact

416 should also be accepted by trainers in their preparation and management of the training process,

417 especially in adolescent female athletes.

418

419 ACKNOWLEDGEMENTS

420 Competing Interests

421 The authors declare there are no competing interests.

422

423

\section{REFERENCES}

424 Ainsworth BE, Haskell WL, Herrmann SD, Meckes N, Bassett Jr DR, Tudor-Locke C, Greer JL, Vezina J, Whitt-Glover MC, Leon AS. 2011. 2011 Compendium of Physical Activities: A Second Update of Codes and MET Values. Medicine \& Science in Sports \& Exercise 43:

427 1575-1581. DOI: 10.1249/MSS.0b013e31821ece12. 
428 Annesi JJ. 2004. Relationship of perceived health and appearance improvement, and self

429

430

431

432

433

434

435

436

437

438

439

440

441

442

443

444

445

446

447

448

449

450

motivation, with adherence to exercise in previously sedentary women. European Journal of Sport Science 4: 1-13 DOI: 10.1080/17461390400074203.

Beaufrère B, Morio B. 2000. Fat and protein redistribution with ageing: metabolic considerations. European Journal of Clinical Nutrition 54: 48-53 DOI: 10.1038/sj.ejcn.1601025.

Bunc V. 2018. A movement intervention as a tool of the influence of physical fitness and health. Trends in Sport Sciences 4: 209-216 DOI: 10.23829/TSS.2018.25.4-6.

Calleja-Gonzalez J, Mielgo-Ayuso J, Sanchez-Ureña B, Ostojic SM, Terrados N. 2019. Recovery in Volleyball. Journal of Sports Medicine and Physical Fitness 59: 982-993. DOI: $10.23736 / \mathrm{S} 0022-4707.18 .08929-6$.

Cohen J. 1988. Statistical power analysis for the behavioral sciences. New Jersey: Lawrence Erlbaum Associates.

Ćopić N, Dopsaj M, Ivanović J, Nešić G, Jarić S. 2014. Body composition and muscle strength predictors of jumping performance: differences between elite female volleyball competitors and nontrained individuals. Journal of Strength \& Conditioning Research 28: 2709-2716. DOI: 10.1519/JSC.0000000000000468.

Ennis CD. 2017. Educating Students for a Lifetime of Physical Activity: Enhancing Mindfulness, Motivation, and Meaning. Research Quarterly for Exercise and Sport 88: 241-250. DOI: 10.1080/02701367.2017.1342495.

Forrestal SG. 2011. Energy intake misreporting among children and adolescents: a literature review. Maternal and Child Nutrition 7: 112-127. DOI: 10.1111/j.17408709.2010.00270.x. 
451 Glinkowska B, Glinkowski WM. 2018. Association of Sports and Physical Activity With

452 Obesity Among Teenagers in Poland. International Journal of Occupational Medicine and

453 Environmental Health 31: 771-782. DOI: 10.13075/ijomeh.1896.01170.

454

455

456

457

458

459

460

461

462

463

464

465

466

467

468

469

470

471

472

Guthold R, Stevens GA, Riley LM, Bull C. 2018. Worldwide trends in insufficient physical activity from 2001 to 2016: a pooled analysis of 358 population-based surveys with 1.9 million participants. The Lancet 6: e1077-e1138. DOI: 10.1016/S2214-109X(18)30357-7.

Haberka M, Stolarz-Skrzypek K, Biedroń M, Szóstak-Janiak K, Partyka M, OlszaneckaGlinianowicz M, Gąsior Z. 2018. Obesity, visceral fat, and hypertension-related complications. Metabolic Syndrome and Related Disorders 16: 521-529. DOI: 10.1089/met.2018.0062.

Haskell WL, Lee IM, Pate RR, Powell KE, Blair SN, Franklin BA, Macera CA, Heath, GW, Thompson PD, Bauman A. 2007. Physical activity and public health. Updated recommendation for adults from the American College of Sports Medicine and the American Heart Association. Circulation 116: 1081-1093. DOI: 10.1161/CIRCULATIONAHA.107.185649.

Hopkins WG. 2000. Measures of Reliability in Sports Medicine and Science. Sports Medicine 30: 1-15. DOI: 10.2165/00007256-200030010-00001.

Janssen I. 2007. Physical activity guidelines for children and youth. Applied Physiology Nutrition and Metabolism 32: 109-121. DOI: 10.1139/H07-109.

Janssen I, Leblanc A. 2010. Systematic Review of the Health Benefits of Physical Activity in School-Aged Children and Youth. International Journal of Behavioural Nutrition and Physical Activity 7: 1-16. DOI: 10.1186/1479-5868-7-40. 
473 Joyner C, Loprinzi PD. 2018. Longitudinal Effects of Personality on Physical Activity Among

474 College Students: Examining Executive Function as a Potential Moderator. Psychological

475 Reports 121: 344-355 DOI:10.1177/0033294117726076.

476 Kahlin Y, Werner S, Edman G, Raustorp A, Alricsson M. Physical self-esteem and personality

477

478

479

480

481

482

483

484

485

486

487

488

489

490

491

492

493

494 traits in Swedish physically inactive female high school students: an intervention study. International Journal of Adolescent Medicine and Health 28: 363-372. DOI:10.1515/ijamh-2015-0017.

Kobzová J, Vignerová J, Bláha P, Krejcovský L, Riedlová J. 2004. The 6th nationwide anthropological survey of children and adolescents in the Czech Republic in 2001. Central European journal of public health 12: 126-130.

Kyle UG, Bosaeus I, De Lorenzo AD, Deurenberg P, Elia M, Manuel Gomez J, Lilienthal Heitmann B, Kent-Smith L, Melchior JC, Pirlich M, Scharfetter H, Schols, AMWJ, Pichard C, ESPEN. 2004. Bioelectrical impedance analysis - part II: utilization in clinical practice. Clinical Nutrition 23: 1430-1453. DOI: 10.1016/j.clnu.2004.09.012.

Kutáč P. 2015. Inter-daily variability in body composition among young men. Journal of Physiological Anthropology 34: 1-7. DOI: 10.1186/s40101-015-0070-6.

Laroche J-A, Girard S, Lemoyne J. 2019. Tracing Adolescent Girls’ Motivation Longitudinally: From FitClub Participation to Leisure-Time Physical Activity. Perceptual \& Motor Skills 126: 986-1005. DOI: 10.1177/0031512519864194.

Lazaar N, Aucouturier J, Ratel S, Rance M, Meyer M, Duché P. 2007. Effect of physical activity intervention on body composition in young children: influence of body mass index status and gender. Acta Paediatrica 96: 1321-1322. DOI: 10.1111/j.1651-2227.2007.00426.x. 
495

496

497

498

499

500

501

502

503

504

505

506

507

508

509

510

511

512

513

514

515

516

517

Liu J, Sun H, Beets MW, Probst JC. 2013. Assessing Natural Groupings of Common LeisureTime Physical Activities and Its Correlates Among US Adolescents. Journal of Physical Activity and Health 10: 470-479. DOI: 10.1123/jpah.10.4.470.

Lobietti R, Coleman S, Pizzichllo E, Merni F. 2010. Landing techniques in volleyball. Journal of Sports Sciences 28: 1469-1476. DOI: 10.1080/02640414.2010.514278.

Malá L, Malý T, Zahálka F, Bunc V, Kaplan A, Jebavy R, Tuma M. 2015. Body Composition of Elite Female Players in Five Different Sports Games. Journal of Human Kinetics 45: 207215. DOI: $10.1515 /$ hukin-2015-0021.

Malina RM. 2007. Body composition in athletes: assessment and estimated fatness. Clinics in Sports Medicine 26: 37-78. DOI: 10.1016/j.csm.2006.11.004.

Malina RM, Geithner, ChA. 2011. Body Composition of Young Athletes. American Journal of Lifestyle Medicine 5: 262-278. DOI: 10.1177/1559827610392493.

Malina RM, Rogol, AD, Cumming SP, Coelho e Silva MJ, Figueiredo AJ. 2015. Biological maturation of youth athletes: assessment and implications. British Journal of Sports Medicine 49: 852-859. DOI: 10.1136/bjsports-2015-094623.

Murakami K, Livingstone MB. 2016. Prevalence and characteristics of misreporting of energy intake in US children and adolescents: National Health and Nutrition Examination Survey (NHANES) 2003-2012. British Journal of Nutrition 115: 294-304. DOI: $10.1017 / \mathrm{S} 0007114515004304$.

Nelson ME, Rejeski WJ, Blair SN, Duncan PW, Judge JO, King AC, Macera CA, CastanedaSceppa C. 2007. Physical activity and public health in older adults: Recommendation from the American College of Sports Medicine and the American Heart Association. Medicine and Science in Sports and Exercise 39: 1435-1445. DOI: 10.1249/mss.0b013e3180616aa2. 
518 Ng M, Fleming T, Robinson M, Thomson B, Graetz N, Margono C. et al. 2014. Global, regional,

519 and national prevalence of overweight and obesity in children and adults during 1980-

520 2013: a systematic analysis for the Global Burden of Disease Study 2013. Lancet 384: 766-

521 81. DOI: 10.1016/S0140-6736(14)60460-8.

522 Nikolaidis PT, Ziv G, Arnon G, Lidor R. 2012. Physical Characteristics and Physiological

523 Attributes of Female Volleyball Players - The Need for Individual Data. Journal of

524 Strength \& Conditioning Research 26: 2547-2557. DOI: 10.1519/JSC.0b013e31823f8c06.

525 Nikolaidis PT. 2013. Body mass index and body fat percentage are associated with decreased

526 physical fitness in adolescent and adult female volleyball players. Journal of Research in

$527 \quad$ Medical Sciences 18: 22-26.

528 Nikolaidis PT, Gkoudas K, Afonso J, Clemente-Suarez VJ, Knechtle B, Kasabalis S, Kasabalis

529 A, Douda H, Tokmakidis S, Torres-Luque G. 2017. Who Jumps the Highest?

530 Anthropometric and Physiological Correlations of Vertical Jump in Youth Elite Female

$531 \quad$ Volleyball Players. Journal of Sports Medicine and Physical Fitness 57: 802-810. DOI:

532 10.23736/S0022-4707.16.06298-8.

533

534 Papadopoulou SD, Papadopoulou SK, Rosemann T, Knechtle B, Nikolaidis PT. 2019. Relative

535 Age Effect on Youth Female Volleyball Players: A Pilot Study on Its Prevalence and

536 Relationship With Anthropometric and Physiological Characteristic. Frontiers in

537 Psychology 10: 2737. DOI: 10.3389/fpsyg.2019.02737.

538 Papadopoulou SD, Zorzou A,Garcia-de-Alcaraz A, Rosemann T, Knechtle B, Nikolaidis PT.

539 2020. Subcutaneous Adipose Tissue in Female Volleyball Players: Is It Related with

$540 \quad$ Performance Indices? Medicina 56: 1-3. DOI: 10.3390/medicina56040159. 
541 Paz GA, Gabbett TJ, Maia MF, Santana H, Miranda H, Lima V. 2017. Physical performance and 542 positional differences among young female volleyball players. Journal of Sports Medicine and Physical Fitness 57: 1282-1289. DOI: 10.23736/S0022-4707.16.06471-9.

544 Riebe D, Franklin BA, Thompson PD, Garber CE, Whitfield GP, Magal M, Pescatello S. 2015.

$545 \quad$ Updating ACSM's Recommendations for Exercise Preparticipation Health Screening.

$546 \quad$ Medicine and Science in Sports and Exercise 47: 2473-2479. DOI:

547 10.1249/mss.0000000000000664.

548

549

550

551

552

553

554

555

556

557

558

559

560

561

562 physical activity summer camp on body composition, metabolic syndrome and physical fitness in obese children. The Journal of Sports Medicine and Physical Fitness 56: 933938.

Scribbans TD, Berg K, Narazaki K, Janssen I, Gurd, BJ. 2015. Heart rate during basketball game play and volleyball drills accurately predicts oxygen uptake and energy expenditure. Journal of Sports Medicine and Physical Fitness 55: 905-913.

Sigmund E, Sigmundová D, Badura P, Kalman M, Hamrik Z, Pavelka J. 2015. Temporal trends in overweight and obesity, physical activity and screen time among Czech adolescents from 2002 to 2014: A National health behaviour in school-aged children study. International Journal of Environmental Research and Public Health 12: 11848-11868. DOI: 10.3390/ijerph120911848.

Tillman MD, Criss RM, Brunt D, Hass CJ. 2004a. Landing constraints influence ground reaction forces and lower extremity EMG in female volleyball players. Journal of Applied Biomechanics 20: 38 -50. DOI: 10.1123/jab.20.1.38. 
563 Tillman MD, Hass ChJ, Brunt D, Bennett GR. 2004b. Jumping and landing techniques in elite $564 \quad$ women's Volleyball. Journal of Sports Science and Medicine 3: 30-36.

565 Tota L, Pilch W, Piotrowska A, Maciejczyk M. 2019. The Effects of Conditioning Training on 566 Body Build, Aerobic and Anaerobic Performance in Elite Mixed Martial Arts Athletes. 567 Journal of Human Kinetics 70: 223-231. DOI: 10.2478/hukin-2019-0033.

568 Troiano RP, Berrigan D, Dodd KW, Mâsse LC, Tilert T, McDowell M. 2008. Physical Activity 569 in the United States Measured by Accelerometer. Medicine \& Science in Sports \& Exercise 40: 181-188. DOI: 10.1249/mss.0b013e31815a51b3.

571 Tsigos C, Hainer V, Basdevant A, Finer N, Fried M, Mathus-Vliegen E, Micic D, Maislos M, Roman G, Schutz Y, Toplak H, Zahorska-Markiewicz B. 2008. Obesity Management Task

573 Force of the European Association for the Study of Obesity. Management of obesity in $574 \quad$ adults: European clinical practice guidelines. Obes Facts 1: 106-16. DOI: $10.1159 / 000126822$.

576 Tsoukos A, Drikos S, Brown LE, Sotiropoulos K, Veligekas P, Bogdanis GC. 2019. Anthropometric and Motor Performance Variables Are Decisive Factors for The Selection of Junior National Female Volleyball Players. Journal of Human Kinetics 67: 163-173. DOI:10.2478/hukin-2019-0012.

Vadiveloo M, Zhu L, Quatromoni PA. 2009. Diet and physical activity patterns of school-aged 581 children. Journal of the American Dietetic Association 109: 145-51. DOI: 10.1016/j.jada.2008.10.012.

Van Gaal LF, Mertens IL, De Block CE. 2006. Mechanisms linking obesity with cardiovascular disease. Nature 444: 875-880. DOI: 10.1038/nature05487. 
585 Valente-Dos-Santos J, Tavares ÓM, Duarte JP, Sousa-E-Silva PM, Rama LM, Casanova JM, 586 Fontes-Ribeiro CA, Marques EA, Courteix D, Ronque ERV, Cyrino ES, Conde J, Coelho587 E-Silva MJ. 2018. Total and regional bone mineral and tissue composition in 588 female adolescent athletes: comparison between volleyball players and swimmers. $B M C$ 589 Pediatrcs 18: 1-11. DOI: 10.1186/s12887-018-1182-z.

590 Vaverka F, Cernosek M. 2013. Association between body height and serve speed in elite tennis 591 players. Sports Biomechanics 12: 30-37. DOI: 10.1080/14763141.2012.670664.

592 Vicente-Rodríguez G, Rey-López JP, Mesana MI, Poortvliet E, Ortega FB, Polito A, Nagy E, 593 Widhalm K, Sjöström M, Moreno LA. 2012. Reliability and Intermethod Agreement for 594 Body Fat Assessment Among Two Field and Two Laboratory Methods in Adolescents. 595 Obesity 20: 221-228. DOI: 10.1038/oby.2011.272.

596 Visnes H, Bahr R. 2013. Training volume and body composition as risk factors for 597 developing jumper's knee among young elite volleyball players. Scandinavian Journal of $598 \quad$ Medicine \& Science in Sports 23: 607-613. DOI: 10.1111/j.1600-0838.2011.01430.x.

599 Woodruff SJ, Meloche RD. 2012. Energy availability of female varsity volleyball players.

$600 \quad$ International Journal of Sport Nutrition and Exercise Metabolism 23: 24-30. DOI:

$601 \quad 10.1123 /$ ijsnem.23.1.24.

602 Zahradnik D, Jandacka D, Holcapek M, Farana R, Uchytil J, Hamill J. 2017. Blocking landing 603 techniques in volleyball and the possible association with anterior cruciate ligament injury, 604 Journal of Sports Sciences 36: 955-961. DOI: 10.1080/02640414.2017.1346817. 
Table $\mathbf{1}$ (on next page)

Revised Table 1 


\section{Table 1:}

2 Numbers and age of participants

\begin{tabular}{lccccc}
\hline Age group & \multicolumn{2}{c}{ Volleyball group (VG) } & \multicolumn{2}{c}{ Control group (CG) } & Difference \\
& $\mathrm{n}$ & $\mathrm{M} \pm \mathrm{SD}$ (years) & $\mathrm{n}$ & $\mathrm{M} \pm \mathrm{SD}$ (years) & years \\
\hline G1 & 27 & $12.32 \pm 0.50$ & 49 & $12.25 \pm 0.49$ & $0.07^{\mathrm{N}+}$ \\
G2 & 42 & $13.75 \pm 0.46$ & 76 & $13.85 \pm 0.51$ & $0.17^{\mathrm{N}+}$ \\
G3 & 31 & $16.08 \pm 0.62$ & 77 & $16.03 \pm 0.48$ & $0.05^{\mathrm{N}+}$ \\
G4 & 30 & $18.06 \pm 0.60$ & 81 & $18.15 \pm 0.53$ & $0.09^{\mathrm{N}+}$ \\
\hline
\end{tabular}

$3 \mathrm{n}$ - frequency, $\mathrm{M}-$ mean, $\mathrm{SD}-$ standard deviation, $\mathrm{N}-$ no significant, $+\mathrm{d} \leq 0.2$

4 
Table 2 (on next page)

Revised Table 2 
1 Table 2:

2 Frequency and volume of weekly physical activity of the female volleyball players

\begin{tabular}{lccccc}
\hline Age group & \multicolumn{2}{c}{ Training / week } & \multicolumn{2}{c}{ Match / week } & Total time (min) \\
& Frequency & Time $(\min )$ & Frequency & Time (min) & \\
\hline VG1 & 3 & 300 & 1 & 60 & 360 \\
VG2 & 4 & 450 & 1 & 60 & 510 \\
VG3 & 4 & 480 & 2 & 100 & 580 \\
VG4 & 4 & 480 & 2 & 100 & 580 \\
\hline
\end{tabular}

3 VG - volleyball group

4 
Table 3 (on next page)

Revised Table 3 


\section{Table 3:}

2 Typical error of body composition parameters

\begin{tabular}{lcc}
\hline Parameters & TEM $(95 \%$ CI $)$ & ICC \\
\hline BM $(\mathrm{kg})$ & $0.02(0.02,0.02)$ & 1.00 \\
TBW $(1)$ & $0.12(0.10,0.13)$ & 1.00 \\
TBW (\%) & $0.22(0.19,0.25)$ & 1.00 \\
BF $(\mathrm{kg})$ & $0.24(0.21,0.27)$ & 1.00 \\
BF $(\%)$ & $0.29(0.25,0.33)$ & 1.00 \\
VFA (cm $\left.{ }^{2}\right)$ & $0.92(0.51,1.05)$ & 1.00 \\
FFM (kg) & $0.23(0.21,0.27)$ & 1.00 \\
SMM (kg) & $0.14(0.12,0.16)$ & 1.00 \\
SMM $_{\mathrm{p}}(\%)$ & $0.16(0.14,0.19)$ & 1.00 \\
\hline
\end{tabular}

$3 \mathrm{BM}$ - body mass, TBW - total body water, BF - body fat, VFA - visceral fat area, FFM - fat

4 free mass, SMM - skeletal muscle mass, TEM - typical error of measurement, $95 \% \mathrm{CI}-$

5 confidence interval, ICC - interclass correlation

6 
Table 4 (on next page)

Revised Table 4 


\section{Table 4:}

2 Mean values of basic parameters $6^{\text {th }}$ NAS and comparison with control group

\begin{tabular}{lccc}
\hline Age group & $\mathrm{BH}(\mathrm{cm})$ & $\mathrm{BM}(\mathrm{kg})$ & $\mathrm{BMI}\left(\mathrm{kg} / \mathrm{m}^{2}\right)$ \\
& $\mathrm{M} \pm \mathrm{SD}\left(6^{\text {th }} \mathrm{NAS}\right)$ & $\mathrm{M} \pm \mathrm{SD}\left(6^{\text {th }} \mathrm{NAS}\right)$ & $\mathrm{M} \pm \mathrm{SD}\left(6^{\text {th }} \mathrm{NAS}\right)$ \\
$\mathrm{Ni}$ & $\mathrm{Ni}$ & $\mathrm{Ni}$ \\
\hline $\mathrm{G} 1$ & $157.6 \pm 7.3$ & $47.1 \pm 9.1$ & $18.9 \pm 3.0$ \\
& $-0.02 \mathrm{SD}$ & $0.01 \mathrm{SD}$ & $-0.03 \mathrm{SD}$ \\
$\mathrm{G} 2$ & $162.0 \pm 6.6$ & $51.3 \pm 8.9$ & $19.5 \pm 2.9$ \\
& $-0.05 \mathrm{SD}$ & $0.21 \mathrm{SD}$ & $0.12 \mathrm{SD}$ \\
$\mathrm{G} 3$ & & & \\
& $166.9 \pm 6.3$ & $58.1 \pm 7.9$ & $20.8 \pm 2.6$ \\
& $0.01 \mathrm{SD}$ & $0.05 \mathrm{SD}$ & $0.05 \mathrm{SD}$ \\
$\mathrm{G} 4$ & & & \\
& $167.3 \pm 6.3$ & $59.5 \pm 8.4$ & $21.2 \pm 2.8$ \\
& $-0.04 \mathrm{SD}$ & $0.22 \mathrm{SD}$ & $0.25 \mathrm{SD}$ \\
\hline
\end{tabular}

$3 \mathrm{BH}$ - body height, BM - body mass, BMI - body mass index, $\mathrm{M}$ - mean, $\mathrm{SD}$ - standard deviation,

$4 \mathrm{Ni}$ - normalization index, $\mathrm{BH}$ - body height, $\mathrm{BM}$ - body mass, $\mathrm{BMI}$ - body mass index, $\mathrm{M}$ - mean,

$5 \mathrm{SD}$ - standard deviation, $\mathrm{Ni}$ - normalization index

6 
Table 5 (on next page)

Revised Table 5 


\section{Table 5:}

2 Differences in somatic parameters between volleyball and control groups

\begin{tabular}{|c|c|c|c|c|}
\hline Parameters & $\begin{array}{l}\text { VG1 vs CG1 } \\
\text { Difference }\end{array}$ & $\begin{array}{c}\text { VG2 vs CG2 } \\
\text { Difference }\end{array}$ & $\begin{array}{c}\text { VG3 vs CG3 } \\
\text { Difference }\end{array}$ & $\begin{array}{c}\text { VG4 vs CG4 } \\
\text { Difference }\end{array}$ \\
\hline $\mathrm{BH}(\mathrm{cm})$ & $0.59^{\mathrm{N}+}$ & $6.03^{* *++}$ & $4.28^{* *++}$ & $4.11^{* *++}$ \\
\hline BM (kg) & $-0.41^{\mathrm{N}+}$ & $1.68^{\mathrm{N}+}$ & $1.22^{\mathrm{N}+}$ & $-0.74^{\mathrm{N}+}$ \\
\hline TBW (1) & $0.46^{\mathrm{N}+}$ & $2.99^{* *++}$ & $2.98^{* * *+++}$ & $2.97^{* * *+++}$ \\
\hline TBW (\%) & $1.42^{\mathrm{N}+}$ & $3.61^{* * *++}$ & $3.58^{* * *+++}$ & $4.69^{* * *+++}$ \\
\hline $\mathrm{BF}(\mathrm{kg})$ & $-0.99^{\mathrm{N}+}$ & $-2.47^{* *++}$ & $-2.86^{* *++}$ & $-4.86^{* * *++}$ \\
\hline BF (\%) & $-1.84^{\mathrm{N}+}$ & $-5.06^{* * *+++}$ & $-4.87^{* * *+++}$ & $-6.48^{* * *+++}$ \\
\hline $\operatorname{VFA}\left(\mathrm{cm}^{2}\right)$ & $-5.03^{\mathrm{N}+}$ & $-9.25^{*++}$ & $-12.32^{*++}$ & $-21.91^{* *++}$ \\
\hline FFM (kg) & $0.58^{\mathrm{N}+}$ & $4.15^{* *++}$ & $4.07^{* * *+++}$ & $4.11^{* * *+++}$ \\
\hline SMM (kg) & $0.39^{\mathrm{N}+}$ & $2.36^{* *++}$ & $2.48^{* * *+++}$ & $2.55^{* * *+++}$ \\
\hline $\operatorname{SMM}_{\mathrm{p}}(\%)$ & $1.24^{\mathrm{N}+}$ & $2.99^{* * *+++}$ & $3.09^{* * *+++}$ & $4.08^{* * *+++}$ \\
\hline
\end{tabular}

$3 \mathrm{BH}$ - body height, BM - body mass, TBW - total body water, BF - body fat, VFA - visceral fat 4 area, FFM - fat free mass, SMM - skeletal muscle mass, SMMp - percentage of SMM in BM,

$5 \quad \mathrm{VG}$ - volleyball group, $\mathrm{CG}$ - control group, $\mathrm{M}$ - mean, $\mathrm{SD}$ - standard deviation, $\mathrm{N}$ - no 6 significant, ${ }^{*} \mathrm{p}<0.05,{ }^{*} \mathrm{p}<0.01, * * * \mathrm{p}<0.001,{ }^{+} d<0.5,{ }^{++} d \geq 0.5,{ }^{+++} d \geq 0.8$ 
Table 6(on next page)

Revised Table 6 
1 Table 6:

2 Differences in the somatic parameter values at increasing chronological age expressed by

3 Cohen's d

\begin{tabular}{lllllll}
\hline Parameters & \multicolumn{2}{c}{12 vs 13 years } & \multicolumn{2}{c}{13 vs 16 years } & \multicolumn{2}{c}{16 vs 18 years } \\
& VG & CG & VG & CG & VG & CG \\
\hline BH $(\mathrm{cm})$ & 1.5 & 0.5 & 0.6 & 0.7 & 0.0 & 0.0 \\
BM (kg) & 0.9 & 0.5 & 0.7 & 0.7 & 0.1 & 0.2 \\
BF (kg) & 0.1 & 0.4 & 0.5 & 0.5 & 0.2 & 0.3 \\
BF $(\%)$ & 0.2 & 0.3 & 0.4 & 0.3 & 0.2 & 0.4 \\
VFA $\left(\mathrm{cm}^{2}\right)$ & 0.2 & 0.3 & 0.4 & 0.4 & 0.1 & 0.3 \\
SMM (kg) & 1.3 & 0.5 & 0.7 & 0.7 & 0.1 & 0.1 \\
SMM $(\%)$ & 0.4 & 0.1 & 0.2 & 0.1 & 0.1 & 0.4 \\
FFM (kg) & 1.2 & 0.5 & 0.7 & 0.7 & 0.1 & 0.0 \\
TBW (l) & 1.2 & 0.5 & 0.7 & 0.7 & 0.1 & 0.0 \\
TBW (\%) & 0.2 & 0.3 & 0.4 & 0.3 & 0.3 & 0.4 \\
\hline
\end{tabular}

$4 \mathrm{BH}$ - body height, BM - body mass, BF - body fat, VFA - visceral fat area, SMM - skeletal

5 muscle mass, FFM - fat free mass, TBW - total body water, VG - volleyball group, CG - control 6 group 
Figure 1

Figure 1 

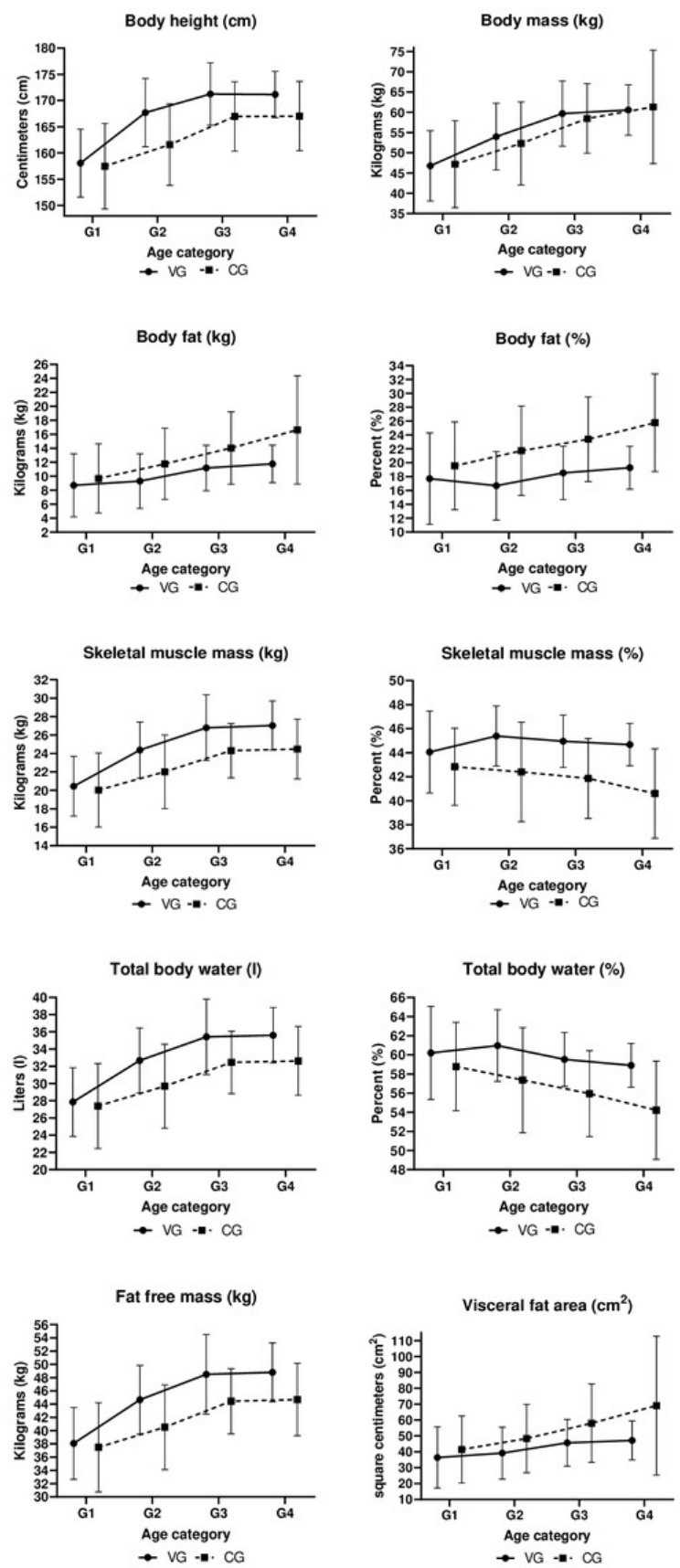